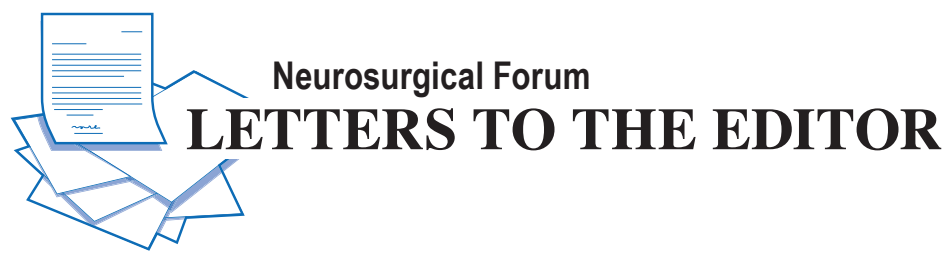

\section{Tranexamic acid for reducing intra- and postoperative blood loss in posterior lumbar interbody fusion: Is it safe enough?}

TO THE EDITOR: We read with great interest the recent article by Kushioka et al. ${ }^{2}$ (Kushioka J, Yamashita T, Okuda S, et al: High-dose tranexamic acid reduces intraoperative and postoperative blood loss in posterior lumbar interbody fusion. J Neurosurg Spine 26:363-367, March 2017), which described the use of intravenous tranexamic acid (TXA) during single-level posterior lumbar interbody fusions. The authors conducted a nonrandomized, retrospective, comparative cohort study with 30 patients in each group (TXA vs no TXA) and found that patients who had received intravenous TXA had lower intraoperative and postoperative blood loss and that TXA administration did not result in any complications. We would like to congratulate the authors for their exciting results, which have helped to clearly outline useful treatment strategies to clinically manage patients undergoing spine surgery with TXA for reducing postoperative blood loss. Nonetheless, we wish to draw attention to the potential complications associated with TXA use by describing our experience.

We encountered a 56-year-old male who was otherwise healthy with no history of seizures and who had undergone an L3-5 transforaminal lumbar interbody fusion for spinal stenosis at our facility. We had intravenously administered $3000 \mathrm{mg}$ of TXA $(7 \mathrm{mg} / \mathrm{kg} / \mathrm{hr})$ and had also applied $2000 \mathrm{mg}$ of TXA on the lumbar spinal wound before closing the wound and placing a drainage tube, which was clamped for 4 hours. Postoperative recovery was unremarkable, and the anesthesiologist confirmed that the patient's condition remained stable. However, the patient experienced one episode of tonic-clonus epilepsy at 5 hours postsurgery, which was managed by administering intravenous single-dose midazolam. A brain CT showed no intracranial lesion, and the final diagnosis of epilepsy was confirmed by a neurologist.

In agreement with our experience, a recent meta-analysis by Lin and $\mathrm{Xiaoyi}^{3}$ reported that the cumulative incidence rate of TXA-associated seizures was $2.7 \%$ and that the incidence rate increased with increasing dosage. Leck- er et al. ${ }^{4}$ have reported the occurrence of TXA-associated seizures during the early postsurgical period after cardiac and non-cardiac surgery and in patients receiving other medical treatments. Such seizures usually occur within the first 5-8 hours after surgery, which corresponds to the period of weaning from intravenous sedation. Further, such events tend to persist for a few minutes but do not progress to status epilepticus. Data from the current literature show the occurrence of sporadic seizures after TXA administration during cardiac surgery, particularly with valve replacement or coronary artery bypass grafting because high doses of TXA are used during these procedures to reduce blood loss. Because TXA and glycine are structural analogs, TXA can bind to glycine receptors as a competitive antagonist and inhibit glycine-activated inhibitory signals, which increases muscle excitability and results in seizures. However, anesthetics, such as propofol, isoflurane, sevoflurane, and desflurane, act as positive allosteric modulators of glycine receptors that can reverse such TXA-mediated inhibition of glycine receptors or midazolam binding to $\mathrm{GABA}_{\mathrm{A}}$ receptor and thereby compensating for the reduction in glycinergic inhibition. ${ }^{4}$ Therefore, seizure episodes occur during the first 5-8 hours postsurgery because while anesthetic levels are rapidly declining in the CNS during this time, TXA levels are either peaking or only slowly declining. ${ }^{4}$ In orthopedic surgery, TXA is usually used as an intravenous infusion or topical application during total knee or total hip arthroplasty., ${ }^{1,5}$ Based on the above mechanism, we cannot exclude the possibility of epilepsy due to TXA use during spine surgery, and surgeons must be aware of the possibility of TXA-related seizures. Such seizures can be easily managed by administering intravenous propofol or midazolam to reverse TXA-induced inhibition of glycinergic receptors.

Yi-Syuan Li, MD Chun-Yu Chen, MD Chi-Hui Chen, MD Zhi-Kang Yao, MD Yu-Hsiang Sung, MD

Kai-Cheng Lin, MD Yih-Wen Tarng, MD

Chien-Jen Hsu, MD Jenn-Huei Renn, MD Kaohsiung Veterans General Hospital, Kaohsiung, Taiwan 


\section{References}

1. Gilbody J, Dhotar HS, Perruccio AV, Davey JR: Topical tranexamic acid reduces transfusion rates in total hip and knee arthroplasty. J Arthroplasty 29:681-684, 2014

2. Kushioka J, Yamashita T, Okuda S, Maeno T, Matsumoto T, Yamasaki R, et al: High-dose tranexamic acid reduces intraoperative and postoperative blood loss in posterior lumbar interbody fusion. J Neurosurg Spine 26:363-367, 2017

3. Lin Z, Xiaoyi Z: Tranexamic acid-associated seizures: a meta-analysis. Seizure 36:70-73, 2016

4. Lecker I, Wang DS, Whissell PD, Avramescu S, Mazer CD, Orser BA: Tranexamic acid-associated seizures: causes and treatment. Ann Neurol 79:18-26, 2016

5. Zhang XQ, Ni J, Ge WH: Combined use of intravenous and topical versus intravenous tranexamic acid in primary total joint arthroplasty: a meta-analysis of randomized controlled trials. Int J Surg 38:15-20, 2017

\section{Disclosures}

The authors report no conflict of interest.

\section{Correspondence}

Chun-Yu Chen: iergy2000@gmail.com.

INCLUDE WHEN CITING

Published online April 27, 2018; DOI: 10.3171/2017.11.SPINE171178.

\section{Response}

We thank Dr. Li et al. for their interest in our study. Their case presentation is noteworthy, and the presented approach to recover from seizure is helpful for other readers. In our previous study, there were no complications including seizure or epilepsy. And there have been no complications at our institution after the study period. However, our patient number was not large enough to detect rare complications. Further research is required to evaluate the complication rate and optimal dose for TXA use during spine surgery.

Junichi Kushioka, MD

Osaka University Graduate School of Medicine, Osaka, Japan

Tomoya Yamashita, MD

Shinya Okuda, MD, PhD

Takafumi Maeno, MD, PhD

Tomiya Matsumoto, MD, PhD

Motoki Iwasaki, MD, PhD

Osaka Rosai Hospital, Osaka, Japan

Ryoji Yamasaki, MD, PhD

Osaka Police Hospital, Osaka, Japan

INCLUDE WHEN CITING

Published online April 27, 2018; DOI: 10.3171/2017.12.SPINE171255.

CAANS 2018, except where prohibited by US copyright law

\section{Tetrad issues exist regarding spinal fusion with pedicle screws and adjacent-segment disease}

TO THE EDITOR: We read the elaborate clinical review article by Agarwal and colleagues ${ }^{1}$ regarding adjacent-segment disease (ASD) following thoracic fusion with pedicle screws (Agarwal N, Heary RF, Agarwal P: Adjacent-segment disease after thoracic pedicle screw fixation. J Neurosurg Spine 28:280-286, March 2018). Indeed, it has been noted that ASD with clinical manifestations might occur as a long-term adverse event for both cervical and lumbar spine fusion. If diagnostic imaging indicates adjacent-segment stenosis or degeneration without clinical symptoms, it is called adjacent-segment degeneration. ${ }^{5}$ Even in lumbar fusion without pedicle screws, ASD occurred in more than $42 \%$ patients with 33 years of follow-up on average. ${ }^{8}$ The current article sheds novel light on ASD following thoracic fusion.

There might be tetrad issues regarding spinal fusion with metal implants. First, the best treatment strategies for ASD remain undefined. Currently, there are several treatment options for ASD, i.e., simple decompression, and fusion with instrumentation extension with or without removal of primary implants. In fact, the underlying mechanisms of ASD remain unclear, yet several hypotheses exist, including increased stress and compression of adjacent segments, the splitting of paraspinal muscles, and the natural degeneration/aging of adjacent discs. ${ }^{8}$

Second, the criteria for pedicle screw implant removal have not reached a consensus. Literature is scant regarding the issue of implant removal, including the timing for removal, the healing of the pedicle after implant removal, and the indications for removal. There were several reports addressing pedicle stress fractures after implant removal, including extension of fusion for the treatment of ASD. ${ }^{6,79}$

Third, serum metal iron levels should be appreciated as systemic reactions to spinal metal implants. Accumulating evidence indicates spinal metal implants, including pedicle screws and metal artificial discs, will cause systemic and local reactions in the human body. For instrumented spinal fusion, serum titanium, niobium, and aluminum levels were significantly elevated, in addition to local metal debris. ${ }^{3,4}$ This potentially harmful issue should be addressed, particularly for children and adolescents undergoing spinal fusion for scoliosis due to the long implant retention time during their remaining lifetime.

Fourth, and most importantly, we propose that the harmful radiation exposure and effective dose reduction of radiographic imaging should be noted. Overwhelming evidence indicates that the cumulative radiation dose from multiple diagnostic radiographies for adolescents with scoliosis increases cancer risks, particularly breast cancer. ${ }^{10}$ With an average of 16 radiographs, 170 patients with adolescent idiopathic scoliosis had a relative risk of 4.8 for developing cancer compared to the age-matched normal Danish population. We noted that Agarwal and colleagues were still adopting traditional spine radiographic imaging, as seen in Fig. 1. To reduce the radiation dose, 
it has been proposed to simply change the radiographic projection from the anteroposterior (AP) to the posteroanterior (PA) direction, ${ }^{2}$ because the radiation-sensitive organs are located at the front of the body. The energy within $\mathrm{x}$-ray beams from back to front attenuates during the penetrating process. The PA spine projections would show up to $64 \%$ lower radiation exposure for children aged 10 years and $65 \%$ for adults compared with AP projections. Therefore, the harmful radiation exposure would be greatly decreased, with a reduced cancer risk. This simple and effective method should be promoted to benefit more and more patients.

Jun Zhang, MD

Baoji Municipal Central Hospital, Baoji, Shaanxi Province, China

Chi-Jiao Ma, MD

Ankang Hospital of Traditional Chinese Medicine, Ankang City, Shaanxi Province, China

Hai-Qiang Wang, MD, PhD

Centre for Translational Medicine, First Affiliated Hospital of Xi'an Jiaotong University, Xi'an, Shaanxi, China

\section{Acknowledgments}

The authors are supported by the National Natural Science Foundation of China (grant no. 81572182).

\section{References}

1. Agarwal N, Heary RF, Agarwal P: Adjacent-segment disease after thoracic pedicle screw fixation. J Neurosurg Spine 28:280-286, 2018

2. Ben-Shlomo A, Bartal G, Mosseri M, Avraham B, Leitner Y, Shabat S: Effective dose reduction in spine radiographic imaging by choosing the less radiation-sensitive side of the body. Spine J 16:558-563, 2016

3. Cundy TP, Antoniou G, Sutherland LM, Freeman BJ, Cundy PJ: Serum titanium, niobium, and aluminum levels after instrumented spinal arthrodesis in children. Spine (Phila Pa 1976) 38:564-570, 2013

4. Cundy TP, Cundy WJ, Antoniou G, Sutherland LM, Freeman BJ, Cundy PJ: Serum titanium, niobium and aluminium levels two years following instrumented spinal fusion in children: does implant surface area predict serum metal ion levels? Eur Spine J 23:2393-2400, 2014

5. Drysch A, Ajiboye RM, Sharma A, Li J, Reza T, Harley D, et al: Effectiveness of reoperations for adjacent segment disease following lumbar spinal fusion. Orthopedics 41:e161-e167, 2017

6. Ha KY, Kim YH: Bilateral pedicle stress fracture after instrumented posterolateral lumbar fusion: a case report. Spine (Phila Pa 1976) 28:E158-E160, 2003

7. Kim SK, Chung JY, Seo HY, Lee WG: Vertebral compression fracture within a solid fusion mass without trauma after removal of pedicle screws. Spine J 16:e219-e223, 2016

8. Lehmann TR, Spratt KF, Tozzi JE, Weinstein JN, Reinarz SJ, el-Khoury GY, et al: Long-term follow-up of lower lumbar fusion patients. Spine (Phila Pa 1976) 12:97-104, 1987

9. Macdessi SJ, Leong AK, Bentivoglio JE: Pedicle fracture after instrumented posterolateral lumbar fusion: a case report. Spine (Phila Pa 1976) 26:580-582, 2001

10. Simony A, Hansen EJ, Christensen SB, Carreon LY, Andersen MO: Incidence of cancer in adolescent idiopathic scoliosis patients treated 25 years previously. Eur Spine J 25:3366-3370, 2016

\section{Disclosures}

The authors report no conflict of interest.

\section{Correspondence}

Hai-Qiang Wang: drwanghq@163.com.

INCLUDE WHEN CITING

Published online May 11, 2018; DOI: 10.3171/2018.1.SPINE1813.

\section{Response}

We appreciate the evaluation of and comments on our study by Wang et al. Given the known prevalence of ASD documented in the literature, especially in the cervical and lumbar spines, we encourage continued study of ASD in the thoracic spine as well. It is our practice to obtain serial upright plain radiographs on follow-up visits to evaluate for bone fusion, spinal alignment, and/or the presence of ASD. As Wang et al. suggested, the cumulative risks of serial imaging are certainly noteworthy for adolescents with scoliosis; however, our study cohort excluded all children. In our reported study, imaging was typically obtained in an AP orientation, immediately after surgery, when the patient was still bedbound. However, we do agree with the sentiment noted by Wang et al., that further imaging should be obtained in a PA orientation in ambulatory patients to limit harmful radiation exposure.

With regard to the necessity for the removal of instrumentation, in our study cohort, this was a rare phenomenon. In general, preserving the soft-tissue envelope at each end of the construct appears to be helpful for limiting the frequency of reoperation for ASD following placement of thoracic pedicle screws. In part, this may be attributed to the anatomy of the thoracic spine that has the benefit of additional support provided by the rib cage. When additional stabilization surgery is required for ASD, we typically extend the construct by two vertebral levels beyond the last instrumented level with a minimum of 4 well-engaged pedicle screws.

Overall, we encourage further studies to validate our radiographic findings of effective stabilization with thoracic pedicle screws on long-term follow-up. We thank Wang et al. for their thoughtful comments.

\section{Nitin Agarwal, MD \\ University of Pittsburgh Medical Center, Pittsburgh, PA \\ Robert F. Heary, MD \\ Rutgers New Jersey Medical School, Newark, NJ \\ Prateek Agarwal, AB}

Perelman School of Medicine, University of Pennsylvania, Philadelphia, PA

INCLUDE WHEN CITING

Published online May 11, 2018; DOI: 10.3171/2018.2.SPINE1847.

CAANS 2018, except where prohibited by US copyright law

\section{Outcomes after spine surgery in adults}

TO THE EDITOR: We read with great interest the article of Dunn et al. ${ }^{2}$ in a recent issue of the journal (Dunn LK, Durieux ME, Fernández LG, et al: Influence of cata- 
strophizing, anxiety, and depression on in-hospital opioid consumption, pain, and quality of recovery after adult spine surgery. J Neurosurg Spine 28:119-126, January 2018). The authors performed a prospective cohort study on 139 patients undergoing spine surgery and concluded that the catastrophizing score, anxiety, and depression play important roles in modulating postoperative pain. The authors should be congratulated for performing a well-designed study on an important topic (e.g., acute pain) in patients undergoing surgery. ${ }^{3,5}$ The current emphasis on the need to use patientcentered outcomes to assess patient recovery after surgery makes the topic relevant in perioperative medicine.,

Although the study of Dunn et al. was well conducted, there are some questions regarding its methods that need to be clarified. First, it is not clear if the authors standardized the intraoperative and postoperative analgesic consumption as this can significantly affect the study outcomes. Second, the authors did not adjust their analysis to accommodate surgical duration as this variable has been shown to be associated with poor outcomes after spine surgery. ${ }^{4}$ Last, the authors performed multiple analyses (more than 10), but did not correct their p value to avoid Type I errors.

We would welcome some comments to address the aforementioned issues, which were not discussed by the authors. This would help to further support the findings of this important study.

\section{Lucas J. Castro-Alves, MD Mark C. Kendall, MD Rhode Island Hospital, Warren Alpert Medical School of Brown University, Providence, RI}

\section{References}

1. Dexter F: Iowa Satisfaction with Anesthesia Scale for regional anesthesia. J Clin Anesth 28:81-82, 2016

2. Dunn LK, Durieux ME, Fernández LG, Tsang S, SmithStraesser EE, Jhaveri HF, et al: Influence of catastrophizing, anxiety, and depression on in-hospital opioid consumption, pain, and quality of recovery after adult spine surgery. $\mathbf{J}$ Neurosurg Spine 28:119-126, 2018

3. Duttchen KM, Lo A, Walker A, McLuckie D, De Guzman C, Roman-Smith $\mathrm{H}$, et al: Intraoperative ketorolac dose of $15 \mathrm{mg}$ versus the standard $30 \mathrm{mg}$ on early postoperative pain after spine surgery: A randomized, blinded, non-inferiority trial. J Clin Anesth 41:11-15, 2017

4. Kim BD, Hsu WK, De Oliveira GS Jr, Saha S, Kim JY: Operative duration as an independent risk factor for postoperative complications in single-level lumbar fusion: an analysis of 4588 surgical cases. Spine (Phila Pa 1976) 39:510-520, 2014

5. McGirt MJ, Bydon M, Archer KR, Devin CJ, Chotai S, Parker SL, et al: An analysis from the Quality Outcomes Database, Part 1. Disability, quality of life, and pain outcomes following lumbar spine surgery: predicting likely individual patient outcomes for shared decision-making. J Neurosurg Spine 27:357-369, 2017

6. Moro ET, Leme FC, Noronha BR, Saraiva GF, de Matos Leite NV, Navarro LH: Quality of recovery from anesthesia of patients undergoing balanced or total intravenous general anesthesia. Prospective randomized clinical trial. J Clin Anesth 35:369-375, 2016

\section{Disclosures}

The authors report no conflict of interest.

\section{Correspondence}

Mark C Kendall: mark.kendall@lifespan.org.

INCLUDE WHEN CITING

Published online May 11, 2018; DOI: 10.3171/2018.2.SPINE18167.

\section{Response}

Thank you to Drs. Castro-Alves and Kendall for their thoughtful and insightful comments regarding our study.

The authors raise the concern of standardization of perioperative care, which may have a significant impact on opioid and nonopioid analgesic consumption. At our institution a dedicated team of neuroanesthesiologists performs all spine cases, and these practitioners follow a standard intraoperative analgesia management algorithm. Furthermore, as stated in the Methods section, postoperative care was administered according to a standardized institutional protocol, with details listed in the paper.

We adjusted for surgical duration in all our analyses, and this is reported as "Mean operation time in mins" in Table 2 and "Operation Length" in Tables 3-5.

It is important to note that our intention was to test for the effect of one specific predictor in each model (e.g., Pain Catastrophizing Scale, depression, anxiety); the remaining variables were included as covariates. We did not test for the effect of multiple variables in any of the models. Therefore correction of the $\mathrm{p}$ value was not necessary.

Lauren K. Dunn, MD, PhD Bhiken I. Naik, MBBCh University of Virginia, Charlottesville, VA

INCLUDE WHEN CITING

Published online May 11, 2018; DOI: 10.3171/2018.2.SPINE18219.

CAANS 2018, except where prohibited by US copyright law

\section{Use of intraoperative vancomycin powder and postoperative infection}

TO THE EDITOR: We read with great interest the article by Adogwa et al. ${ }^{1}$ (Adogwa O, Elsamadicy AA, Sergesketter A, et al: Prophylactic use of intraoperative vancomycin powder and postoperative infection: an analysis of microbiological patterns in 1200 consecutive surgical cases. J Neurosurg Spine 27:328-334, September 2017). The authors report on a large, 1200-patient study on vancomycin powder use in adults undergoing spinal deformity correction at their institution between 2011 and 2013 with a minimum 3-month follow-up. Surgical site infection (SSI) following spine surgery is a costly complication associated with significant morbidity and mortality. Topical vancomycin has emerged as a potential low-cost, low-toxicity tool to reduce the rates of infection. However, clinical results have varied, and the utility of topical vancomycin in spine surgery continues to be controversial.,4-6 Given the higher risk of infection in spinal deformity patients, ${ }^{7}$ their paper adds much-needed data on vancomycin use in a population that may benefit from its application. 
We had a few questions regarding the methodology in this paper. The patients in this study received 1-7 $\mathrm{g}$ of intraoperative crystalline vancomycin powder. This is a fairly wide range, with doses higher than those reported in the literature, which are typically around $1-2 \mathrm{~g}$. Although dosing should ideally be based on body weight, the authors did not specify their dosing strategy. We would also appreciate a distribution for the dosing in their study population.

The authors mentioned that traumatic, infectious, and neoplastic cases were excluded, but they did not provide a breakdown of the indications for surgery. We wanted to clarify whether all 1200 cases were truly for deformity correction procedures, or if patients with deformity undergoing procedures such as decompression and fusion were included in this cohort. This number of cases would be in the upper limit of a normal range for adult spinal deformity correction at a single institution in the given time span. We would very much appreciate the authors stratifying their inclusion criteria, as it was not clearly defined in the paper.

Many spine surgeons have adopted the use of vancomycin powder. And although studies suggest that the use of vancomycin powder is a safe and efficacious practice, much of the existing literature is based on level III evidence. ${ }^{2,4-6}$ Additionally, the Centers for Disease Control and Prevention (CDC) Guideline for the Prevention of Surgical Site Infection states as follows: "2B.1. Do not apply antimicrobial agents (ie, ointments, solutions, or powders) to the surgical incision for the prevention of SSI. (Category 1B-strong recommendation; low-quality evidence.)."3 Given this recommendation and the concern for the development of antibiotic resistance, vancomycin powder should be utilized judiciously in multilevel spine surgeries until further robust evidence is established.

This article is a much-needed addition to the literature, and we congratulate the authors on a successful publication. As it stands, the role of vancomycin powder in spine surgery remains unclear and further high-quality studies are needed to investigate the safety and efficacy of this intervention in select populations.

Andrew S. Moon, $\mathbf{B S}^{1,2}$ Sakthivel R. Manoharan, MD2

${ }^{1}$ Tufts University School of Medicine, Boston, MA 2University of Alabama at Birmingham, Birmingham, AL

\section{References}

1. Adogwa O, Elsamadicy AA, Sergesketter A, Vuong VD, Mehta AI, Vasquez RA, et al: Prophylactic use of intraoperative vancomycin powder and postoperative infection: an analysis of microbiological patterns in 1200 consecutive surgical cases. J Neurosurg Spine 27:328-334, 2017

2. Bakhsheshian J, Dahdaleh NS, Lam SK, Savage JW, Smith ZA: The use of vancomycin powder in modern spine surgery: systematic review and meta-analysis of the clinical evidence. World Neurosurg 83:816-823, 2015

3. Berrios-Torres SI, Umscheid CA, Bratzler DW, Leas B, Stone EC, Kelz RR, et al: Centers for Disease Control and Prevention guideline for the prevention of surgical site infection, 2017. JAMA Surg 152:784-791, 2017 (Erratum in JAMA Surg 152:803, 2017)

4. Chiang HY, Herwaldt LA, Blevins AE, Cho E, Schweizer ML: Effectiveness of local vancomycin powder to decrease surgical site infections: a meta-analysis. Spine J 14:397-407, 2014

5. Kang DG, Holekamp TF, Wagner SC, Lehman RA Jr: Intrasite vancomycin powder for the prevention of surgical site infection in spine surgery: a systematic literature review. Spine J 15:762-770, 2015

6. Khan NR, Thompson CJ, DeCuypere M, Angotti JM, Kalobwe E, Muhlbauer MS, et al: A meta-analysis of spinal surgical site infection and vancomycin powder. J Neurosurg Spine 21:974-983, 2014

7. Smith JS, Klineberg E, Lafage V, Shaffrey CI, Schwab F, Lafage R, et al: Prospective multicenter assessment of perioperative and minimum 2-year postoperative complication rates associated with adult spinal deformity surgery. J Neurosurg Spine 25:1-14, 2016

\section{Disclosures}

The authors report no conflict of interest.

\section{Correspondence}

Sakthivel R. Manoharan: srajaram@uabmc.edu.

\section{INCLUDE WHEN CITING}

Published online May 25, 2018; DOI: 10.3171/2018.1.SPINE1867.

\section{Response}

No response was received from the authors of the original article.

CAANS 2018, except where prohibited by US copyright law 